\title{
Approaches Used by Nurses in the Care of Patients with Nasogastric Intubation (NG Tubes) at the Laquintinie Hospital Douala Cameroon
}

\author{
Samuel Nambile Cumber ${ }^{1,2}$ *, Ngo Minette Akama ${ }^{2}$, Lydia Agbor-Mbeng Nkongho \\ ${ }^{1}$ Discipline of Public Health Medicine, Department of Nursing \& Public Health, College of Health Sciences, University of Kwazulu-Natal, \\ Durban, South Africa \\ ${ }^{2}$ Under Privileged Children and Women Assistance (UPCAWA-SWEDEN), Branch Researcher, Buea, Cameroon
}

Email address:

samuelcumber@yahoo.com (S. N. Cumber)

${ }^{*}$ Corresponding author

\section{To cite this article:}

Samuel Nambile Cumber, Ngo Minette Akama, Lydia Agbor-Mbeng Nkongho. Approaches Used by Nurses in the Care of Patients with Nasogastric Intubation (NG Tubes) at the Laquintinie Hospital Douala Cameroon. Journal of Family Medicine and Health Care.

Vol. 2, No. 4, 2016, pp. 30-35. doi: 10.11648/j.jfmhc.20160204.12

Received: September 23, 2016; Accepted: October 1, 2016; Published: November 2, 2016

\begin{abstract}
The general objective of this work was to assess approaches used by the nurses at the Laquintinie Hospital Douala in the care of patients with NG Tubes and so identify the challenges nurses faced when caring for patients with NG tubes. It was a descriptive cross sectional study design carried out from April to June, the sample technique and study population involved 20 nurses working at the medical, paediatric intensive care unit and the surgical unit, the data was collected using an observation and interview guide. The result collected shows that only (53\%) of the nurse were able to manage patient effectively. From the findings of this work it is concluded that only few of the nurses could actually carry out care on patient with NG tubes effectively and all (75\%) of the nurses who had carried out nasogastric intubation on patients had challenges like patient refusal to coorperate as they were educated on the importance of the procedure. Based on the findings the following recommendations were made like, the nurses at the L.H.D should attend seminars on the different strategies used in the care of patients with NG tubes. The nurses should also go in for more research on internet, textbooks and journals.
\end{abstract}

Keywords: Nasogastric, Intubation, Patience, Cameroon

\section{Introduction}

Nasogastric intubation is a medical process involving the insertion of a plastic tube (Nasogastric tube or NG Tube) through the nose, past the throat, and down into the stomach. [1] Orogastric intubation is a similar process involving the insertion of a plastic tube (Orogastric Tube) through the mouth. Nasogastric feeding is usually considered as the first line in artificial nutrition support for patients with a functioning gastrointestinal tract whose nutritional needs cannot be met by diet alone or by diet and nutritional supplements. [1,2]

Nasogastric gastric tube insertions are carried on by nurses, junior doctors and sometimes by anaesthetists in the theatre. [1-3] A registered nurse may commence NG tube once it has been prescribed by the medical officer or dietician. [3]
However in the underdeveloped countries, sometimes the nurse may insert NG tube if her nursing diagnoses make provision especially in the absence of a medical doctor.

Nasogastric intubation which is an advanced nursing procedure is used for feeding, administration of medication and laboratory diagnoses. [1, 4] It is vital that nurses inserting them know the correct insertion technique care and as well as procedure for verifying their correct positioning, hence to successfully carry out this procedure the nurse should have in possession the certificate of S. R. N., BSc. and Masters in Nursing. [4, 5] Historically, it seems using tubes for feeding patients goes back at 3500 years to ancient Greek and Egyptian civilizations. [5]

Papyrus evidences suggested that Egyptian physicians 
used reeds and animal bladders to rectally feed patient things like wine, milk, whisky, broth and so on to treat a range of complaints. [6]

Capivacceus in 1598, used a hollow tube with a bladder attached to one end, filled with some form of nutrient solution, down as far as a patient's esophagus. [7, 8] The beautifully named Agvapendente used a form of nasophargngeal tube in 1617 , the forerunner of NG tubes, but only going as far as the pharynx. [7, 8]

Theoretically, according to the United States Conference of Catholic Bishops in 2001, they state "there should be a presumption in favour of providing nutrition and hydration to all patients including patients who require medically assisted nutrition and hydration as long as this is of sufficient benefit to outweight the burden involves to the patient. [9-11] On March $20^{\text {th }} 204$, Pope John Paul II addressed participants at a four-day conference sponsored by the Pontifical Academy for Life and the International Federation of Catholic Medical Associations. [10, 11] He addressed the issue of artificial hydration and nutrition in patient, he said, "if patients are not dying, artificial nutrition in principle, ordinary and proportionate and as such, morally obligatory, in so far as and until it seen to have attained its proper finality, which in the present consist in providing nourishment to the patient and alleviation of his suffering. [9-11]

From the conceptual aspect, patients who are unable to eat or drink, NG intubation and feeding is one way to ensure patient received adequate nutrition and medication. [10] Also, NG intubation is a less invasive alternative to surgery in the event, an intestinal obstruction can be removed easily without surgery. [1] Despite some disadvantages associated with NG tube, a child can do well with NG tube for several years. $[4,5,7]$

Nasogastric tubes are widely used in the world's hospital, yet in spite of the fear campaigning to expose the dangers, still patient are dying from the complication of wrong insertion, further clinical research is needed in this care, but small studies suggested that magnet-tracking devices where a magnet is inserted into the tip may hold promise for the future. $^{2}$ The modern soft and atraumatic NG tubes are made up of polyurethane which becomes more soft on exposure to patient's body temperature. $[1,2]$

Also the National Patient Safety, made some recommendations stating that individual risk assessment should be carried out prior to nasogastric tube feeding. [3, 4, 6] The absences of respiratory distress should not be interpreted for correct placement and acidity/alkalinity should not be tested using blue litmus paper, while "whoosh" test should be cease immediately. [8]

Nurses seem to be scared in caring for NG Tube patients while some nurses seem not to be aware of the of the patients needs with an NG Tube and the specific care required. $[1,4]$ This is why the researcher thought it wise to research on this topic so as to close the gaps and fear associated with NG Intubation.

Some research questions where:

i. Do Nurses at the Laquintinie Hospital Douala know the indications for Nasogastric Intubation?

ii. Do Nurses at the Laquintinie Hospital Douala know the nursing interventions being given to a patient with nasogastric tube?

iii. What challenges do the nurses at the Laquintinie hospital Douala face in the care of patient with NG tubes?

Some objectives for these study where: To assess approaches used by the nurses at the Laquintinie hospital Douala in the care of patient with NG tubes.

i). To investigate the indications of nasogastric intubation.

ii). To identify nursing interventions being given to a patient with a nasogastric tube.

iii). To identify the challenges, face by nurses face when caring for a patients with NG tubes.

The importance of this study is to raise awareness on the importance of care given to patients with NG Tubes and how it could prevent some complications and promote recovery hence limiting patients stay in the hospital.

This study is titled "Approaches Nurses used in the care of patients with nasogastric tubes at the Laquintinie hospital Douala which was conducted from April $19^{\text {th }}$ to June $18^{\text {th }}$ 2016.

During the study, there were a number of limitations that were posed which include:

- Some of the nurses refused to answer the questions that were posed in the interview guide, since it was optional, they claim they were busy and had been out of school for a long time.

- More so, method of communication was a problem, as some claimed not to understand English language at all.

- The length of time used to approve administrative clearance was also a problem, since the general supervisor found it difficult to approve administrative clearance on time.

- Despite the difficulties encountered sufficient data was obtained and hence made a production of this work a reality.

\section{Methods and Materials}

\subsection{Study Design and Duration}

A Hospital based descriptive cross-sectional study employing both interview and observation. The study design was done to determine the "Approaches used by nurses in the care of patient with nasogastric tubes". This study necessitated sampling the opinion of the respondent in relation to variables under investigation.

The study lasted for 2 months.

\subsection{Definition of Terms}

Nasogastric Intubation: Is a tube design to access the stomach through the nose, nasophargnx and esophagus for examination, treatment or other purposes.

- Nursing: Is a helping and independent profession that provides services that contribute to the health of the people. 
- Catheter: A Flexible tube for insertion into a narrow opening so that fluid may be introduced or removed.

\subsection{Study Area}

This study was carried out at the Laquintinie Hospital Douala (LHD). Douala which is located at the Littoral region of Cameroon, it is the economic capital of Cameroon that is, it si based on commercial and industrial activities, since most of the home industries are found in Douala. The L.H.D is or reference hospital situated in the heart of Bonako quarter (Akwa). It is bounded at the North by "La Palais Dika Akwa", at the South by the Ngodi cemetery, in the West by La Salle des Fetes d'Akwa" and the East by the Akwa polyclinic. The Laquintinie hospital Douala has many building about 38 pavilions an external consultation block and 600 employed people with a capacity of 710 beds.

It is made up of the following units:

- Medical unit divided into: Enterogastrology unit, cardiology, medical A and B

- Paediatric unit which is divided into: paediatric. A stage, paediatric B, paediatric Reanimation neonatal section.

- Maternity unit which is divided into: the labour room, maternity A. B, C, D, E and G sector for premature babies.

- The surgical unit which is divided into: surgical A, B, C and D.

- Psychiatric unit.

- Others includes: the emergency department, pharmacy, laboratory, ultrasound, and x-ray room economic, the central administration and mortuary.

\subsection{Study Population}

This study comprises of nurses and ward charges of all age group, level of training and working experiences, who were willing to participate in the study.

\subsection{Sample Size and Sampling Technique}

The sample size consists of 20 nurses including ward charges, convenient sampling technique was used, and the targeted population was made up of nurses who work in the paediatric, medical intensive care unit and surgical unit with different level of training and working experiences.

\subsection{Inclusion Criteria}

This study includes all the nurses in the Laquintinie hospital Douala who work in the paediatric, medical intensive care unit and surgical unit.

\subsection{Exclusion Criteria}

Those who were excluded in this study were: medical doctors, lab technicians, nurses who have never carried out NG intubation, student doctors and student nurses.

\subsection{Research Instrument}

A well structured interview and observational guide was designed base on the objectives. Also, pen, pencil, ruler and papers were used. In order to ease understanding, libraries, internets, websites were all used.

\subsection{Authorisation and Ethical Consideration}

An authorization was obtained that is a consent form, from the administration of St. Francis Higher Institute of Nursing and Midwifery in Buea, which was submitted to the General Supervisor of Laquintinie Hospital Douala. After a careful examination this was approved and we were directed on how to go about. All information were kept confidential and the importance of the research were explained to nurses involve in the study.

\subsection{Data Analysis}

The data generated from the study was entered into a Microsoft Excel page the data was analyzed using tables to ease understanding of the data. Sampling was carried out through purposeful random sampling where any nurse who was willing to participate was included in the study.

\section{Results}

\subsection{Demographic Data}

A total of 20 nurses of age range 30 and above were involved in the study carried out at the Laquintinie Hospital Douala from April to June.

From the data collected all the $20(100 \%)$, nurses were female and Christians with different working experiences of 3-5 years $12(60 \%)$, and 6-10 years, $8(40 \%)$, as shown in table 1 these nurses also presented with different qualifications, 5 (25\%), were nursing assistants, $11(55 \%)$, were SRN, $1(5 \%)$ is HND, $2(10 \%)$, were BSc and $1(5 \%)$, were masters holders.

Table 1. Distribution of Respondents by Age, working experience and Qualification

\begin{tabular}{llll}
\hline Factor & Category & Frequency & Percentage \\
\hline Age & $30-35$ & 10 & $50 \%$ \\
\multirow{2}{*}{ Working experience } & $36-40$ & 10 & $50 \%$ \\
& $3-5$ years & 12 & $60 \%$ \\
qualification & $6-10$ years & 8 & $40 \%$ \\
& Nursing assistant & 5 & $25 \%$ \\
& SRN & 11 & $55 \%$ \\
& HND & 1 & $5 \%$ \\
& BSc & 2 & $10 \%$ \\
& Masters holders & 1 & $5 \%$ \\
\hline
\end{tabular}

Table 2. Distribution of Respondents' Religion.

\begin{tabular}{lll}
\hline Religion & Frequency & Percentage \\
\hline Christians & 35 & $70 \%$ \\
Muslims & 10 & $20 \%$ \\
Others & 5 & $10 \%$ \\
Total & 50 & $100 \%$ \\
\hline
\end{tabular}

With regards to religion majority, $35(70 \%)$ of respondents were Christians, $10(20 \%)$ were Muslims and $5(10 \%)$ 
belonged to others.

\subsection{Nurses Knowledge on the Indications of N. G Tube}

Table 3. Nurses response on what are the indications of N. G. tube.

\begin{tabular}{lll}
\hline Factor & Frequency & Percentage \\
\hline Drug administration & 20 & $40 \%$ \\
treatment of ileus bowel or obstruction & 25 & $50 \%$ \\
For enteral feeding & 5 & $10 \%$ \\
Total & 50 & $100 \%$ \\
\hline
\end{tabular}

The result presented in table3 shows that, 20 (40\%) of respondents gave drug administration as an indication for N.G tube, $25(50 \%)$ said for treatment of ileus and $5(10 \%)$ said for enteral feeding.

Table 4. Nurses' response on what are the contra indications of $N$. G intubation.

\begin{tabular}{lll}
\hline Factor & Frequency & Percentage \\
\hline severe mid face trauma & 12 & $60 \%$ \\
Recent nasal surgery & 5 & $25 \%$ \\
excessive manipulation during placement & 3 & $15 \%$ \\
Total & 20 & $100 \%$ \\
\hline
\end{tabular}

As represented on table 4: $12(60 \%)$ of the respondents were of the opinion that severe mid face trauma is contraindicated for intubation, $5(25 \%)$ said recent nasal surgery and $3(15 \%)$ also said patients in coma are contraindicated.

Table 5. Nurses response on the complications of $N$. G intubation.

\begin{tabular}{lll}
\hline Factor & Frequency & Percentage \\
\hline Diarrhoea & 37 & $74 \%$ \\
Nausea and vomiting & 10 & $20 \%$ \\
Aspiration of food contents & 3 & $6 \%$ \\
Total & 50 & $100 \%$ \\
\hline
\end{tabular}

As represented on table 5; 37 (74\%0 knew diarrheal as a complication for N. G intubation, $10(20 \%)$ said nausea and vomiting and $3(6 \%)$ gave aspiration of food as one of the complications of N. G intubation.

Table 6. Nurses response on the nursing intervention of patients with N.G intubation.

\begin{tabular}{lll}
\hline Factor & Frequency & Percentage \\
\hline Explain procedure to the patient & 30 & $60 \%$ \\
Set up iv line & 15 & $30 \%$ \\
Examine the nostrils for deformity & 5 & $10 \%$ \\
Total & 50 & $100 \%$ \\
\hline
\end{tabular}

From the data collected; $30(60 \%)$ of the respondents say explain procedure to the patient, $15(30 \%)$ were of the opinion that set up IV line and $5(10 \%)$ said examine the nostrils for deformity.

Table 7. nurses response on nursing intervention before the procedure.

\begin{tabular}{lll}
\hline Factor & Frequency & Percentage \\
\hline Informed consent & 40 & $80 \%$ \\
Ask if any allergies & 9 & $18 \%$ \\
Any nose surgery & 1 & $2 \%$ \\
Total & 50 & $100 \%$ \\
\hline
\end{tabular}

From the data collected; $40(80 \%)$ of the respondents were of the opinion that informed consent should be obtained, 9 $(18 \%)$ knew that they should ask of any allergies and $1(2 \%)$ said they will ask if any nose surgery before the procedure.

Table 8. Nurses response on nursing intervention after the procedure.

\begin{tabular}{lll}
\hline Factor & Frequency & Percentage \\
\hline Monitor input and output & 22 & $44 \%$ \\
Skin and abdomen & 26 & $52 \%$ \\
Vital signs & 2 & $4 \%$ \\
Total & 50 & $100 \%$ \\
\hline
\end{tabular}

With regards to table $7 ; 22$ (44\%) said monitor input and output, $26(52 \%)$ said skin and abdomen and $2(4 \%)$ also said vital signs monitor are nursing interventions after the procedure.

\subsection{Nurses Knowledge on the Challenges Faced When Caring for a Patient with N. G tube}

Table 9. Nurses' response on challenges faced in the care.

\begin{tabular}{lll}
\hline Factor & Frequency & Percentage \\
\hline Challenges from patients refusal & 20 & $40 \%$ \\
Challenges by refusal of members & 15 & $30 \%$ \\
Challenges from block tube and patients refusal & 15 & $30 \%$ \\
Total & 50 & $100 \%$ \\
\hline
\end{tabular}

From the data collected: $20(40 \%)$ of the nurses faced challenges from patients refusal $15(30 \%)$ faced challenges from family members refusal and $15(30 \%)$ of the nurses had challenges from blocked tubes and patient refusal.

Table 10. Nurses' response on solutions that were implemented.

\begin{tabular}{lll}
\hline Factor & Frequency & Percentage \\
\hline $\begin{array}{l}\text { Patients and family members were given health } \\
\text { education on the importance of the procedure }\end{array}$ & 35 & $70 \%$ \\
$\begin{array}{l}\text { Blocked tubes were removed and the importance } \\
\text { of the procedure emphasized }\end{array}$ & 15 & $30 \%$ \\
Total & 50 & $100 \%$ \\
\hline
\end{tabular}

From the data collected, all the 35 (70\%) nurses who had challenges implemented health education on the importance of the procedure to the patients and family members as a solution to the challenges faced from patient's and family members refusal,15(30\%) of the nurses removed blocked tubes and the importance of the procedure emphasized.

\section{Discussion}

\subsection{Nurses Knowledge on the Indications of N. G tube}

From the results above it could be seen that $20(40 \%)$ of the nurses knew drug administration as an indication of N. G. tube, $25(50 \%)$ said treatment of ileus or bowel obstruction is another indication of .N. G tube which is in accordance with who stated that gastro intestinal decompression using nasogastric tube is important for the treatment of patients with bowel obstruction or prolonged ileus while $5(10 \%)$ of the nurses gave enteral feeding as another indication of nasogastric intubation as seen in table 3. [12] 
Based on the contraindications of nasogastric intubations, $12(60 \%)$ of the nurses knew the different contraindication of nasogastric intubation as they stated that severe mild face trauma is contraindicated for nasogastric intubation, 5 (25\%) gave recent nasal surgery as another contraindications for nasogastric intubation also, 3 (15\%) of nurses saw excessive manipulation during placement as a contraindication for nasogastric intubation which is in line with Dourgault and Bercik, which stated that excessive manipulation or movement by the patient during placement including coughing as seen in table 4 . [10, 11]

With regards to the complications of nasogastric intubation, $37(74 \%)$ of nurses knew diarrheal as a complication for nasogastric intubation as $10(20 \%)$ of the nurses gave nausea and vomiting as another complication of nasogastric intubation and $3(6 \%)$ of the nurses said aspiration of food contents is also a complication of nasogastric intubation which is in line with Stock, which stated that diarrheal nausea and vomiting, aspiration of food are complication of nasogastric intubation. [13] As seen in table 5.

\subsection{Nurses Knowledge on the Intervention on Patients with Nasogastric Intubation}

As represented on nursing intervention on patients with nasogastric intubation $30(60 \% 0$ of the nurses explain procedure to the patient, $15(30 \%)$ of the nurses set up iv line and $5(10 \%)$ of the nurses examine the nostrils for deformity which are nursing interventions of patients with nasogastric intubation which is in line with Stock, Broke, Smeltszer, which stated that explain the procedure, benefit, risk, complication and also examine the patients nostrils for septal deviation. [13-15]

Also, nurses knowledge on the nursing intervention before the procedure, $40(80 \%)$ of the nurses signed informed consent before the procedure as $9(18 \%)$ of the nurses ask the patient if any allergies before the procedure and $1(2 \%)$ of the nurses ask if any surgery before the procedure which is in line with Grol. [12]

Based on nurses knowledge on nursing intervention after the procedure, $22(44 \%)$ of the nurses gave monitoring input and output as an intervention after the procedure, $26(52 \%)$ said monitor skin and abdomen and $2(4 \%)$ also said that vital signs monitor after the procedure which is in line with Merck Manual of diagnosis and therapy, which says that, the nurse will keep track of the amount of liquid the patient takes in, and the amount he sends out by measuring the amount of urine out. [1, 2] The nurse should check for blood pressure, heart rate, breathing rate and temperature, they should also ask about pain.

\subsection{Challenges Faced by Patients in the Care of Patients with N. G tube}

According to the data collected, 20 (40\%) nurses who had carried out N. G intubation on patient faced challenges, 15 (30\%0 nurses had challenges by family members refusal and $15(30 \%)$ nurses had had challenges from blocked tube and patient refusal.

Also, with regard to these challenges faced, some solutions were given as $35(70 \%)$ nurses gave health-education to patients and family members $15(30 \%)$ nurses removed block tubes and the importance of the procedure emphasized.

\section{Conclusion}

Based on the data collected and careful analysis of data, it can be concluded that:

i). Majority of the nurses at the Laquintinie hospital Douala knows the indications of nasogastric

ii). Intubations.

iii). Nurses at the Laquintinie hospital Douala know the nursing interventions given to a patient with NG tube.

iv). The nurses at the Laquintinie hospital Douala faces some challenges in the care of patients with NG tubes such as patient and family member refused and block tubes.

\section{Recommendation}

Based on the analysis of data collected and careful examination of the result the following recommendations were made:

i). The nurses at the L. H. D should attend seminars on the different strategies used in the care of patients with NG tubes.

ii). The nurse should also go in for more research on internet, textbooks and journals.

\section{References}

[1] Sano, N., Yamamoto, M., Nagai, K., Yamada, K., \& Ohkohchi, N. (2016). Nasogastric tube syndrome induced by an indwelling long intestinal tube. World Journal of Gastroenterology, 22(15), 4057-4061. http://doi.org/10.3748/wjg.v22.i15.4057

[2] Vinay, H. G., Raza, M., \& Siddesh, G. (2015). Elective Bowel Surgery with or without Prophylactic Nasogastric Decompression: A Prospective, Randomized Trial. Journal of Surgical Technique and Case Report, 7 (2), 37-41. http://doi.org/10.4103/2006-8808.185654

[3] Tsai Y. F., Luo CF, illias A., Lincc, Hu Hp. Nasogastric tube insertion in anesthetized and intubated patients: A New and reliable method; BMC Gastroenterol, 2012: 12-99. Williams T.M, (2016). Nasogastric tube feeding: a safe option for patients? Br J Community Nurs. 2016 Jun-Jul; Suppl Nutrition: S28-31. doi: 10.12968/bjen.2016.21.Sup7.S28.

[4] Fan L, Liu Q, Gui L, (2016). Efficacy of nonswallow nasogastric tube intubation: a randomised controlled trial. J Clin Nurs. 2016 May 24. doi: 10.1111/jocn.13398. [Epub ahead of print]

[5] Nejo T, Oya S, Tsukasa T, Yamaguchi N, Matsui T, (2016). Limitations of Routine Verification of Nasogastric Tube Insertion Using X-ray and Auscultation: Two Case Reports of Life-Threatening Complications. Nutr Clin Pract. 2016 May 13. pii: 0884533616648324 . [Epub ahead of print]. 
[6] Saima S, Asai T, Okuda Y. The Use of a Tracheal Tube for Guiding Nasogastric Tube Insertion. Masui. 2016 Apr; 5(4):421-3.

[7] Manning CT, Buinewicz JD, Sewatsky TP, Zgonis E, Gutierrez K, O'Keefe MF, Freeman K. Does Routine Midazolam Administration Prior to Nasogastric Tube Insertion in the Emergency Department Decrease Patients' Pain? (A Pilot Study). Acad Emerg Med. 2016 Jul; 23 (7): 766-71. doi: 10.1111/acem.12961.

[8] Bureau of Medicine and Surgery. Department of the Nauy 2300 E Street NW Washington, D. C. 20372-5300, Operational Medicine Health Care in the Military Settings CAPT Michael John Hughey, MC, USNR, NAUMED P-5139 (2011).

[9] National Patient Safety Agency (2007). Advice to the NHS on reducing harm caused by the misplacement of nasogastric feeding tubes. Update February 2007, Nasogastric incidents: Summary update London: NPSA. $\mathrm{http}: / /$ tinyurl.com/nasogastric-feeding

[10] Dourgault, A. M., Ipe, L., Wealler, J., Swartz, S. \& O’Dea: P. J.
(2007). Knowledge of enteral feeding development of evidence-based guidelines and critical care nurses. 27 (4), 1729. Retrieved from http://cca.aacnjournals.org/content/27/4/17.full.pdf

[11] Bercik P., Schlageter V. Marvo M. Rawlinson J. Kucera P., Amstrong D., Non Invasive Verification of NG tube placement using a magnet-tracking system JPEN J. Parenter Enteral Nutrition $(2005,29$ (4: 305-10).

[12] Grol R., Wensing M. Eales M.: Improving Patient Care: The Implementation of Change in Clinical Practice. Heinemann Edinburgh: Elsevier Butterworth: 2005.

[13] Stock, A. et al., (2008), Confirming Nasogastric tube position in the emergency department. $\mathrm{pH}$ testing is reliable. Pediatric Emergency Care: 24: 12, 805-9

[14] Brook, C. and Waught, A. (2007/Foundation of Nursing Practice. Fundamentals of Holistic care $3^{\text {rd }}$ Ed. London. J.B. Lippincott, Company p2. 48-130.

[15] Smeltszer, S. C., Bare, B. G. (2004). Brunner \& Suddarth's Textbook of Medical Surgical Nursing. Philadelphia Lippincott. 